\title{
The Common Travel Area
}

\author{
IMELDA MAHER
}

\subsection{Introduction}

The Common Travel Area (CTA) is an arrangement among the UK, the Crown Dependencies (the Bailiwick of Jersey, the Bailiwick of Guernsey and the Isle of Man) and Ireland by which British and Irish citizens can move freely and reside in either jurisdiction and enjoy associated rights and privileges, including the right to work, study and vote in certain elections, as well as to access social welfare benefits and health services. These arrangements have been disrupted by Brexit even though these arrangements long preceded Ireland's and the UK's membership of the EU.

The retention of the CTA was largely uncontroversial for either state or for the EU when the UK chose to leave the EU. Nonetheless, Brexit has had two major effects: first, it heightened its visibility as it received considerable political and media attention in the early stages of the Brexit negotiations; second, Brexit crystallized the CTA through formalizing it while both governments and the EU have allowed for its continued development. Thus, the CTA has moved from being a highly informal arrangement to becoming a cluster of laws, with an intergovernmental Memorandum of Understanding (MOU) and the Protocol and legislation most notably found in the Brexit statutes of Ireland and the UK. ${ }^{1}$ It is a distinct legal arrangement, recognized by and connected to but operating separately from the Withdrawal Agreement (WA) and the Trade and Cooperation Agreement (TCA) which should insulate it to some degree from concerns surrounding the Protocol.

${ }^{1}$ Immigration and Social Security Co-ordination (EU Withdrawal) Act 2020 (UK); Withdrawal of the United Kingdom from the European Union (Consequential Provisions) Act 2020 (Ireland). 


\subsection{The CTA Pre-Brexit}

The CTA emerged over time and almost by default following the creation of the Irish state in 1922. Irish citizens were not classified as aliens under the UK British Nationality Act $1948,{ }^{2}$ and in Ireland a Statutory Instrument exempted British citizens from the Aliens Act 1935, with it remaining in place after the Immigration Act 2004. ${ }^{3}$ Citizens from either state were not subject to routine immigration controls and enjoyed extensive rights and privileges in the other state; so, in effect, there were no additional formalities for citizens from either state moving to live and work in the host state. ${ }^{4}$ This largely informal arrangement was disrupted only during the Second World War, being renewed by an exchange of letters between the governments shortly thereafter. ${ }^{5}$ The CTA seemed to work well for migrant citizens from both states, being largely invisible.

The first formal recognition of this arrangement was, ironically, in the 1999 EU Treaty of Amsterdam. Article 2 of what is now Protocol 20 noted that 'the United Kingdom and Ireland could continue to make arrangements between themselves relating to the movement of persons between their territories ("the Common Travel Area")'. The CTA was exempt from the application of those EU laws giving effect to Europe without Frontiers (Schengen) as it was itself an area without frontiers for the two islands. The exemption was justified by both geography and

2 See also s 2(1) Ireland Act 1949, s 1(3) and now s 3Za Immigration Act 1971, introduced by s 2 Immigration and Social Security Co-ordination (EU Withdrawal) Act 2020. For those entering the UK from Ireland who are not Irish citizens, see the Immigration (Control of Entry through Republic of Ireland) Order 1972. For detailed operational guidance, see the Home Office memorandum for staff, 'The Common Travel Area v. 8', 5 January 2021.

3 See now Aliens (Amendment) (No 2) Order, 1999 SI No 24/1999. See also s 4 of the 2004 Act and ss 11 and 12, as amended by s 114 Withdrawal of the United Kingdom from the European Union (Consequential Provisions) Act 2020, and see Chapter 11 in this volume.

${ }^{4}$ B Ryan, 'The Common Travel Area between Britain and Ireland' (2001) 64 Modern Law Review 855; I Maher, 'Crossing the Irish Law Border after Brexit: The Common Travel Area and the Challenge of Trade' (2018) Irish Yearbook of International Law 51; G Butler and G Barrett, 'Europe's "Other" Open-Border Zone: The Common Travel Area under the Shadow of Brexit' (2018) 20 Cambridge Yearbook of European Legal Studies BELS 252.

${ }^{5}$ E Meehan, 'The Origins of the Common Travel Area between Ireland and the United Kingdom and Its Fate in an Era of Governmental Concern about Undocumented Migration and International Terrorism', European Migration Network (Ireland) and Economic and Social Research Institute Research Conference on Documenting Irregular Migration (Dublin, 8 December 2011). S de Mars, CRG Murray, A O'Donoghue and B Warwick, 'Discussion Paper on the Common Travel Area', Northern Ireland Human Rights Commission and the Irish Human Rights and Equality Commission 2018, 22. 
politics, given that the 1998 Agreement was only one year old at that stage and the demilitarization of the land border between Northern Ireland and Ireland was being effected. ${ }^{6}$

\subsection{Brexit and the CTA}

\subsubsection{The Protocol}

Echoing Protocol 20 of the Treaty on the Functioning of the European Union (TFEU), Article 3(1) of the Northern Ireland Protocol notes that the two states can continue to make arrangements under the CTA, subject to two related caveats. First, both states must fully respect the rights of natural persons conferred by EU law and second, the UK has to ensure that the CTA can apply without affecting the obligations Ireland has under EU law, in particular in relation to free movement to, from and within Ireland for EU citizens and their family members, irrespective of nationality. ${ }^{7}$ Subject to this caveat, it will be possible for British citizens coming to Ireland to enjoy more expansive rights than those of EU citizens living in Ireland. This retains the status quo, as British and Irish citizens have always had privileges that went further than those of other EU citizens whom they hosted. The difference is that British citizens are now third-country nationals under EU law and that the EU in the WA accepts the logic that led to Protocol 20 TFEU and the British/ Irish exemption from Schengen. Ireland will remain outside Schengen, choosing an area without frontiers with the UK instead. This means that Irish, as well as British, citizens will be subject to passport controls on entry to other EU members.

\subsubsection{The CTA Memorandum of Understanding}

One key question for the UK-EU negotiations leading to the WA was to determine what encompassed the CTA. ${ }^{8}$ This question did not arise so starkly at the time of the Amsterdam Treaty, but, given the need to determine relations with the UK as a third country, the EU needed to

${ }^{6}$ E Fahey, 'Swimming in a Sea of Law: Reflections on Water Borders, Irish (British) Euro Relations and Opting-Out and Opting-In after the Treaty of Lisbon' (2010) 47(3) Common Market Law Review 673.

7 Art 3(2) Protocol.

${ }^{8}$ Common Travel Area Information Note from Ireland to the Article 50 Working Group 15 March 2017. 
know what it was acknowledging. To gain greater recognition for the CTA, it had to be formalized. This led to the MOU in May 2019 between Ireland and the UK. ${ }^{9}$ The MOU states that it builds on the 'excellent and highly valued' co-operation that already exists under the CTA. ${ }^{10}$ Both governments published a joint statement alongside the MOU asserting their mutual commitment to maintaining the CTA in all circumstances. ${ }^{11}$ The scope and limitations of these expansive statements can then be seen in the remainder of the MOU and the fact that it expressly says that it is not legally binding. ${ }^{12}$

The MOU clarified that the CTA consists of two elements. First (see Section 14.3.3 for the second), the CTA itself is concerned with the ability to move freely. ${ }^{13}$ It was this ability to cross borders that came to the fore when negotiations began on Brexit, as the issue of how the border for goods was to be secured between the UK and the EU had to be determined. The CTA ensures no routine migration controls for Irish citizens at UK borders, although there may be checks for certain purposes, ${ }^{14}$ and passengers are required to produce ID when passing through Irish airports. ${ }^{15}$ There are no border posts at the land border with Northern Ireland, seen as an essential underpinning for, and consequence of, the 1998 Agreement. It is an invisible border. ${ }^{16}$ These aspects of free

9 The CTA also extends to the Crown Dependencies (Isle of Man, Guernsey and Jersey); see Home Office memorandum for staff (n 2) 7. S de Mars and CRG Murray, 'With or Without EU? The Common Travel Area After Brexit' (2020) 21 German Law Journal 815.

${ }^{10}$ Art 2.

${ }^{11}$ Joint statement of 8 May 2019 between the UK government and the government of Ireland on the CTA. The CTA has been restricted by Covid-19 with both states requiring, at times, a specific Covid negative test prior to travel and quarantine, subject to limited exceptions between GB and Ireland. Different rules apply for Wales and Scotland, raising interesting questions as to the scope of the CTA under devolution in the UK. There were no limitations on travel across the land border on the island of Ireland.

12 Art 17.

${ }^{13}$ Arts 3 and 6 Memorandum of Understanding between the Government of Ireland and the Government of the United Kingdom of Great Britain and Northern Ireland concerning the Common Travel Area and Associated Reciprocal Rights and Privileges, May 8 2019; s 3Za Immigration Act 1971.

${ }^{14}$ In the UK, under s 3ZA(1)(3) Immigration Act 1971, an Irish citizen can be excluded where that is conducive to the public good.

15 Art 3 Aliens (Amendment) (No 3) Order 1997 which allows checks at Irish borders on those coming from the UK. And when building a new terminal in Dublin airport, no provision was made for arrivals from the CTA.

${ }^{16}$ UK Government, 'Northern Ireland and Ireland', Position Paper (16 August 2017); Maher (n 4) 7; C Gormley-Heenan and A Aughey, 'Northern Ireland and Brexit: Three Effects on "the Border in the Mind"' (2017) 19(3) British Journal of Politics and International Relations 497, 499. 
movement are referred to only obliquely in legislation in both jurisdictions, however, and neither jurisdiction confers a positive right in these respects. Hence in the UK statute, Irish citizens do not require leave to enter or remain in the UK, and in the Irish statute British citizens are not included in the definition of alien, or, more recently, non-national. ${ }^{17}$ It is no wonder that Hogan $J$ (as he then was) referred to the CTA as requiring 'legal archaeology. ${ }^{18}$

\subsubsection{The Memorandum of Understanding: Rights and Privileges}

The second, and significant, aspect of the MOU is its clarification of the extensive reciprocal rights and privileges for British and Irish citizens in each territory which both governments state are of immense importance to them and, notably, will continue to evolve over time. ${ }^{19}$ Thus, the MOU, while formalizing arrangements, suggests both durability and flexible evolution. This future evolution was also allowed for under the Protocol, concluded six months later. These newly codified rights and privileges show the extent to which the CTA is not just concerned with travel across borders. As they are reciprocal, they should not be changed unilaterally, although they do not map exactly onto each other - a product in part of scattered legal bases and variation in legal frameworks as between the two states. ${ }^{20}$ Both governments commit to taking any necessary steps to ensure provision of these rights and privileges and clarity around their availability for citizens and service providers, up to and including legislation or other bilateral agreements. ${ }^{21}$

The key reciprocal rights and privileges set out in the MOU are, first, the right to reside, a right which the two governments are to ensure that they continue to provide for in statute. The UK government did this in 2020; the Irish legislation remains more oblique: British citizens are not classified as non-nationals. ${ }^{22}$

${ }^{17}$ In the UK, s 3Za Immigration Act 1971 and in Ireland, ss 11 and 12 Immigration Act 2004, as amended.

18 Pachero v Minister for Justice [2011] IEHC 491.

19 Arts 4, 7-13 MOU.

${ }^{20}$ De Mars and Murray (n 9) 820. The UK had reviewed the CTA unilaterally in 2008, suggesting either that 2008 was an aberration or that this statement has more of an aspirational than binding quality. On the 2008 reforms, see Fahey (n 6) 680.

21 Arts 14 and 15 MOU.

22 Ss 3ZA and 9 Immigration Act 1971 (as amended) and ss 11 and 12 Immigration Act 2004 (as amended). 
Second, the rights to work and to be self-employed are protected. As Irish and British citizens are regarded as settled in their host state, all that is required is proof of citizenship in order to secure a British national insurance number or an Irish personal public service number and to take up employment or set up a business. No special permissions are required. A more complex question is the mutual recognition of qualifications. ${ }^{23}$ Both governments commit to comprehensive measures allowing for such recognition in line with national law. ${ }^{24}$ Urgent calls for an overarching bilateral agreement or programme have not yet led to action. ${ }^{25}$ Instead, with 182 regulated professions and regulation of them delegated, this is a slow and complex process. ${ }^{26}$ In many instances, the relevant professional body needs to act; for example, the Law Societies of Ireland and England and Wales reinstated prior mutual recognition arrangements (governed by EU law), allowing admission of their respective solicitors without the need to take qualifying examinations. ${ }^{27}$

Third, the right to health care is protected: citizens resident in the host state have the right to access emergency, routine and planned (specialized) publicly funded health services on the same basis as citizens of that state. $^{28}$ The two governments signed an additional MOU in December 2020 recognizing that health care would be available irrespective of citizenship, an MOU being necessary given that EU cross-border health care for residents would no longer be available. ${ }^{29}$ The MOU addresses posted workers, frontier workers, students, state reimbursement arrangements and data protection.

23 The quality assurance bodies for higher education in both states (QQI and QAA) renewed their MOU on information sharing and mutual understanding of quality and reputation of higher education in Ireland and the UK, December 2018.

${ }^{24}$ Art 8 CTA MOU. See now: 'Update: Developments from July 2021 to September 2021' at the front of this book.

25 A Isaac, 'UK and Ireland Urged to Recognize Professional Qualifications Post-Brexit' (10 February 2021) www.politico.eu/article/uk-and-irish-governments-urged-toguarantee-professional-qualifications/.

26 In Ireland at least, see the Professional Human Resources Body, CIPD Practical Guide to Brexit, www.cipd.ie/news-resources/practical-guidance/guides/brexit-faqs\#89311.

27 'Law Society Offers Open Access to Irish Roll, Post-Brexit', Law Society Gazette, 1 April 2021.

28 Art 9 MOU given effect in Ireland by Part 2, Withdrawal of the United Kingdom from the European Union (Consequential Provisions) Act 2020 and related statutory instruments.

29 MOU concerning Common Travel Area Healthcare Arrangements (in recognition of Residency-Based Health Systems), 18 December 2020. The TCA includes British citizens in emergency health-care arrangements when on a temporary stay in the EU with the British government issuing a Global Health Insurance Card. 
Fourth, the right to social protection is provided for. This is one of the very few areas under the CTA where the governments concluded a number of (binding) agreements, most recently in 2019. ${ }^{30}$ It sets out a principle of equality of treatment for the citizens of both states and their families. It lists the main benefits and allowances available in both jurisdictions, including any amendments to them in the future, while expressly excluding any rights or benefits arising under EU law, underlining the fact that the CTA exists in parallel to Irish rights and obligations as an EU member state.

Fifth, the right to housing is addressed: the CTA gives a right of access to social housing, including supported housing and homeless assistance, on the same basis as citizens of the host state. ${ }^{31}$

The principle of equality of treatment also applies in the realm of education, the sixth area mentioned in the MOU. ${ }^{32}$ It extends beyond access to all levels of education and training to associated student support, on a reciprocal basis. ${ }^{33}$ The UK has left the ERASMUS scheme for students to study at another EU university for part of their degree. ${ }^{34}$ The Irish government has offered to extend the scheme to all Northern Irish students (whether or not they are Irish citizens) ${ }^{35}$ with discussions ongoing with Irish higher education institutions as to how best to implement this commitment.

Finally, the CTA confers political rights, particularly important in Northern Ireland as those who choose to identify as Irish under the 1998 Agreement can exercise the right of franchise on the same basis as those who identify as British. Citizens resident in either host state can register to vote in both parliamentary and local elections on the same basis as citizens of that state. ${ }^{36}$

30 Art 10 MOU on the CTA; Convention on Social Security 1 February 2019.

31 Art $11 \mathrm{MOU}$ on the CTA. In the UK see the Persons Subject to Immigration Control (Housing Authority Accommodation and Homelessness) Order 2000 SI 2000/706 which includes those covered by the CTA in social housing support and assistance.

32 Art 12 MOU on the CTA, with a July 2021 MOU on Education (for which, see 'Update: Developments from July 2021 to September 2021' at the front of this book).

${ }^{33}$ In Ireland, see the Student Support Act 2011 (as amended), in particular s 14. In the UK, see the Education (Student Fees, Awards and Support) (Amendment) Regulations 2021 SI 2021/127.

${ }^{34}$ Introducing instead the Turing scheme: see Department of Education and Gavin Williamson MP, 'New Turing Scheme to Support Thousands of Students to Study and Work Abroad', Press Release, 26 December 2020.

${ }^{35}$ M Devine, 'NI Students Could Be Able to Avail of Erasmus Scheme in September' Belfast Telegraph (15 March 2021). See further 'Update: Developments from July 2021 to September 2021' at the front of this book.

36 Art 13 CTA MOU, the UK Representation of the People Act 1983 and the Irish Electoral Act 1992. The change in Irish law arose out of the 1998 Agreement as voting rights had not been reciprocal prior to that. 
Thus, the scope of the CTA extends far beyond the freedom to travel. It encapsulates a significant number of social rights and the right to vote. While the MOU and the Social Security Convention have codified these arrangements, the underlying legislation remains scattered and can be either extended or reduced. The CTA remains fundamentally a pragmatic arrangement, albeit one now framed with an explicit and shared commitment by both governments to its importance. At the same time, it is not framed in terms of fundamental rights, it is legally scattered and it is limited to Irish and British citizens. ${ }^{37}$

\subsubsection{CTA Governance and Visas}

Under the MOU, there is an oversight committee of officials that is to meet at least annually. ${ }^{38}$ This complements the CTA Forum on Immigration Matters, which co-ordinates on visa and migration by citizens of other states. The Forum, consisting of senior officials from both states, meets at least twice a year, reporting to respective ministers on an ongoing basis. ${ }^{39}$ Its operational and policy sub-groups share information on operation and enforcement and drive implementation of the programme of work on rendering secure external borders. ${ }^{40}$ The operation of these bodies remains largely opaque. ${ }^{41}$ Each state enforces the other's terms and conditions for entry for other citizens and works closely on protecting their borders. ${ }^{42}$ While there is close collaboration on border controls, the arguably greater significance of the CTA for the Irish government means that it has been seen to align itself with UK policy. ${ }^{43}$ The states have a common visa policy for Indian and Chinese

37 Although the Convention on Social Security extends to family members. On citizenship rights, see Chapter 15 in this volume.

38 Art 16.

39 Joint Ministerial Statement on Co-operation on Measures to Secure the External Common Travel Area Border, 20 December 2011. Art 7.

40 Art 7, Ministerial answer to Parliamentary Question in the Dáil, 15 November 2016, PQ 56, Frances Fitzgerald TD. The Forum is co-chaired by the heads of the UK Border Agency, the Home Department, and the Irish Naturalisation and Immigration Service (INIS) of the Department of Justice.

${ }^{41}$ Compare for example, with the bodies set up and meeting under the Protocol. See Chapter 4 in this volume.

42 Joint Ministerial Statement. For the UK, see Immigration (Control of Entry through Republic of Ireland) Order 1972 (as amended) and the Home Office memo to staff (n 2) 31, 40 and 59. For Ireland, see Aliens (Amendment No 3) Order 1997.

43 See de Mars and Murray (n 9) 817. 
citizens and their separate visa policies are broadly consistent. ${ }^{44}$ The lack of formality at the border can catch the unwary non-Irish or nonBritish citizen moving between the two states, especially across the invisible land border. ${ }^{45}$

\subsection{Conclusion}

The issue of borders has grown more significant as Brexit emphasizes the external borders between the EU and the UK. Brexit drew attention to the CTA and its continuation was relatively uncontroversial. It is an exception to new constraints on free movement of people between the EU and the UK, allowing British and Irish citizens to move freely and to live and work in each state. The greatest source of concern is the land border which, following the 1998 Agreement, has become largely invisible, or, at least, frictionless. ${ }^{46}$ The total number of person border crossings is around 110 million annually, with 15 main crossings on the $500 \mathrm{~km}$ border. ${ }^{47}$ The frequency of border crossings (both land and air) highlights the strong basis for continuing this arrangement defined more by pragmatism than by law.

The CTA goes far beyond movement across borders, however. It is primarily concerned with facilitating citizens from the two states living and working in each state on a more-or-less equal basis. The earnest commitment of both governments to the significance of the CTA set out in the MOU is undermined by the fact that the MOU itself is not legally binding and by the complexity of the domestic legal rules in both states underpinning it. Nonetheless, the MOU does provide greater clarity as to

${ }^{44}$ SI 473/2014 Immigration Act 2004 (Visas) Orders 2014 (for Ireland). For the UK, see Home Office memo to staff (n 2) 31; T McGuinness and M Gower, 'The Common Travel Area, and the Special Status of Irish Nationals in UK Law', House of Commons Library Briefing Paper No 7661 (9 June 2017); Maher (n 4) 62.

${ }^{45}$ Kweder $v$ Minister for Justice [1996] 1 IR 381; Pachero v Minister for Justice [2011] IEHC 491; G Butler, 'Not a "Real" Common Travel Area: Pachero v. Minister for Justice and Equality” (2015) 54 Irish Jurist 155.

46 Maher (n 4) 69.

47 More than 112,000 British citizens live in Ireland (2.5 per cent of the population of Ireland) while about 380,000 people born in Ireland live in the UK, of which 38,000 live in Northern Ireland. See generally Central Statistics Office, 'Brexit-Ireland and the UK in Numbers' (December 2016) (Ireland); UK Office for National Statistics, 'Living Abroad: Dynamics of Migration between the UK and Ireland' (17 September 2017) 15. Because those born in Northern Ireland can claim citizenship, it is more complicated to calculate numbers with the UK statistics referring to those born in Ireland while Irish figures tend to refer to Irish citizens. Maher (n 4) 53. 
the CTA principles and core rights and privileges. As a discrete, longstanding pragmatic arrangement between the two states that is 100 years old next year, the CTA is relatively robust and is likely to survive the political and legal challenges currently surrounding the borders between the EU and the UK. 